$10-2004$

\title{
The Non-Destructive and Nano-Microstructural Characterization of Thermal-Barrier Coatings
}

\author{
Y. H. Sohn \\ B. Jayaraj \\ University of Central Florida \\ S. Laxman \\ University of Central Florida \\ B. Franke \\ University of Central Florida \\ J. W. Byeon \\ University of Central Florida
}

University of Central Florida, ysohn@mail.ucf.edu

See next page for additional authors

Follow this and additional works at: https://engagedscholarship.csuohio.edu/enme_facpub

Part of the Mechanical Engineering Commons

How does access to this work benefit you? Let us know!

Publisher's Statement

The final publication is available at Springer via http://dx.doi.org/10.1007/s11837-004-0292-2

\section{Original Citation}

Sohn, Y. H., Jayaraj, B., Laxman, S., 2004, "The Non-Destructive and Nano-Microstructural Characterization of Thermal-Barrier Coatings," JOM, 56(10) pp. 53-56.

This Article is brought to you for free and open access by the Mechanical Engineering Department at EngagedScholarship@CSU. It has been accepted for inclusion in Mechanical Engineering Faculty Publications by an authorized administrator of EngagedScholarship@CSU. For more information, please contact library.es@csuohio.edu. 


\section{Authors}

Y. H. Sohn, B. Jayaraj, S. Laxman, B. Franke, J. W. Byeon, and Anette M. Karlsson 


\title{
The Non-Destructive and Nano-Microstructural Characterization of Thermal-Barrier Coatings
}

\author{
Y.H. Sohn, B. Jayaraj, S. Laxman, B. Franke, J.W. Byeon, and A.M. Karlsson
}

Authors' Note: More information on the authors' research and education activities can be obtained from mmae.ucf.edu/ ysohn and me.udel.edu/karlsson.

The durability of thermal barrier coatings (TBCs) plays an important role in the service reliability and maintainability of hot-section components in advanced turbine engines for aerospace and utility applications. Photostimulated luminescence spectroscopy (PSLS) and electrochemical impedance spectroscopy (EIS) are being concurrently developed as complimentary nondestructive evaluation (NDE) techniques for quality control and liferemain assessment of TBCs. This paper discusses recent achievements in understanding the residual stress, phase constituents, and electrochemical resistance (or capacitance) of $T B C$ constituents - with an emphasis on the thermally grown oxide. Results from NDE by PSLS and EIS are correlated to the nano- and microstructural development of TBCs.

\section{INTRODUCTION}

Thermal-barrier coatings (TBCs) consisting of 7-8 wt.\% $\mathrm{Y}_{2} \mathrm{O}_{3}$ stabilized $\mathrm{ZrO}_{2}$ (YSZ), applied by air-plasma spray (APS) (Figure 1a), or electron-beam physical vapor deposition (EB-PVD) (Figure 1b), play a critical role in the performance and reliability of modern gas turbine engines. ${ }^{1-4}$ The insulating YSZ coatings are deposited on internally-cooled hot-section components and provide a thermal gradient between the hot exhaust gas and the metallic surface. Oxygen diffuses through the ceramic coating and oxidizes the alumina-forming $\mathrm{MCrAlY}(\mathrm{M}=\mathrm{Ni}$ and/or $\mathrm{Co}$ ) or (Ni,Pt)Al bond coats, which is an intermediate coating layer between the YSZ and the superalloy. As a result of oxidation, the thermally grown oxide (TGO), consisting primarily of $\alpha-\mathrm{Al}_{2} \mathrm{O}_{3}$, forms and grows with associated growth stress.

In addition to mechanical load associated with the use-pattern of a gas turbine, TBCs are subjected to thermomechanical load during thermal cycling due to the thermal expansion mismatch between the metallic substrate and the ceramic coatings. The effect of the thermal mismatch alone can give rise to stresses as high as $4 \mathrm{GPa}$ in the TGO at room temperature..$^{5-7}$ Thus, failures frequently occur during cooling or once ambient temperature is reached. The damage evolution up to the final failure

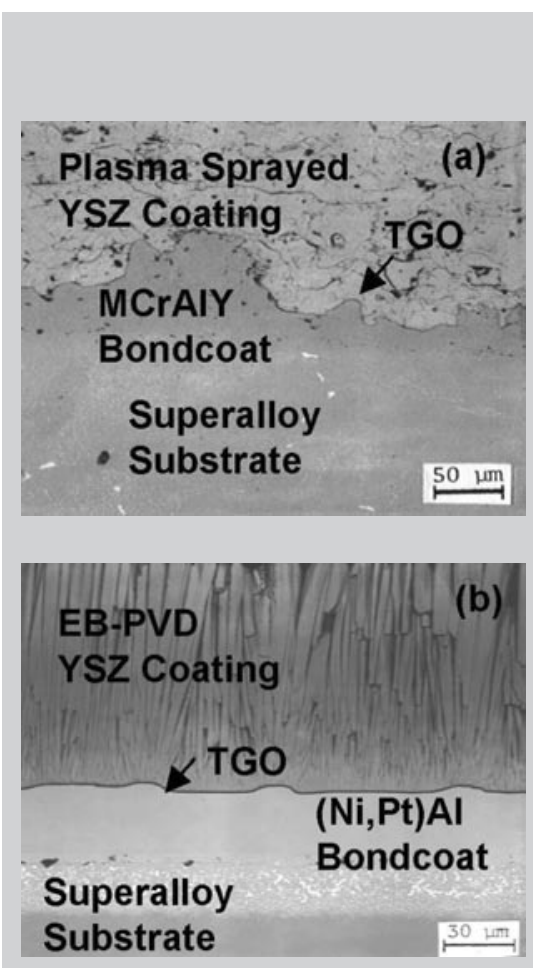

Figure 1. Backscattered electron micrographs of the (a) APS and (b) EB-PVD TBCs. is often related to a complex evolution of the microstructure, where damage during thermo-mechanical cycling initiates at multiple interfacial flaws in the vicinity of the TGO. With continued cycling the flaws eventually link up and the TBCs fail by the spallation of the TGO and/or YSZ coating. After TBC spallation, the bond coat is directly exposed to high-temperature gas, leading to accelerated degradation of the bond coat and superalloy components. ${ }^{1-4,8,9}$

Since TBC failure frequently involves component failure and unscheduled maintenance of gas turbine engines, it is important that the integrity of TBCs be nondestructively evaluated by examining the characteristics of TBCs including residual stress, thickness and the phase constituents of the TGO, as well as the presence of any insipient damage. Non-destructive evaluation (NDE) of these characteristics can provide critical information regarding the damage/failure modes of TBCs and can be a part of parameters monitored for lifetime management of TBCs and engine operation.

The development of TBCs with enhanced durability and reliability along with a mechanism-based life prediction model require refined understanding of failure mechanisms based on detailed analysis at the nano- and microscopic scale, coupled with mechanics-based failure evaluation. The focus in this paper will be on novel tools for nanoand microstructural analysis. Some investigations on microstructural development using transmission-electron microscopy (TEM) and scanning TEM (STEM) have been reported, ${ }^{10-14}$ but specimen preparation of thermally cycled TBCs has been difficult due to the extremely fragile nature of specimens with multiple interfaces. 


\section{PSLS AND EIS: COMPLIMENTARY NDE TECHNIQUES}

Critical factors typically associated with the spallation failure include the thickness of the TGO, the residual stress of the TGO, and the phase constituents, especially the polymorphic transformation of the $\mathrm{Al}_{2} \mathrm{O}_{3}$ in the TGO scale. ${ }^{1-4,15}$ These three characteristics of TBCs can be examined non-destructively by using both photostimulated spectroscopy (PSLS) and electrochemical impedance spectroscopy (EIS). However, failure mechanisms are unique for each TBC system. There is, for example, no unique value for maximum TGO thickness. ${ }^{16}$ Nor is there one critical TGO stress that can be used for all systems. ${ }^{5-7}$ Instead, TGO stress has to be selected for the particular system used and must be based on structural evaluation linked to mechanisms-based modeling.

The use of PSLS as an NDE technique for TBCs was pioneered by Clarke and refined by several researchers. ${ }^{5,6,17-26} \mathrm{The}$ governing principles and the applicability of PSLS has been extensively reported,,$^{5,6,17-26}$ particularly for the determination of residual stress of the $\alpha-\mathrm{Al}_{2} \mathrm{O}_{3}$ in the TGO scale, and polymorphic phase constituents of $\mathrm{Al}_{2} \mathrm{O}_{3}$ (e.g., $\gamma, \theta$, and $\alpha$ phases).

Figure 2 represents a typical evolution

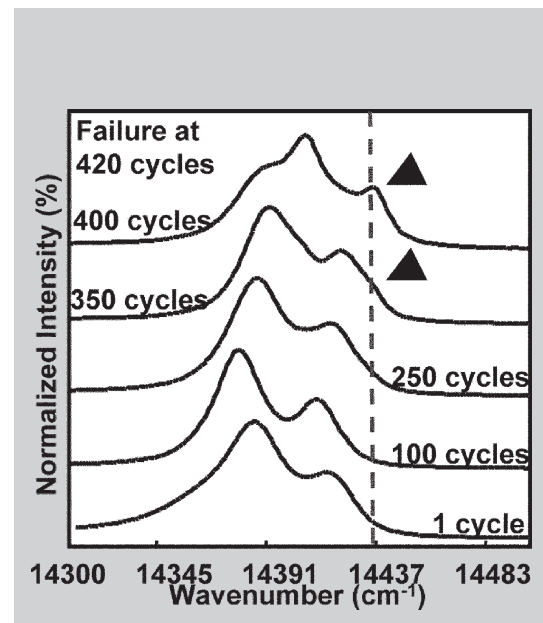

Figure 2. The typical photostimulated luminescence spectra as a function of 1 $h$ thermal cycling for EB-PVD TBCs with (Ni,Pt)Al bond coats. The TBC spallation occurred after 420 cycles while the luminescence from stress-relieved TGO scale (marked by arrows) was observed starting 350 cycles.
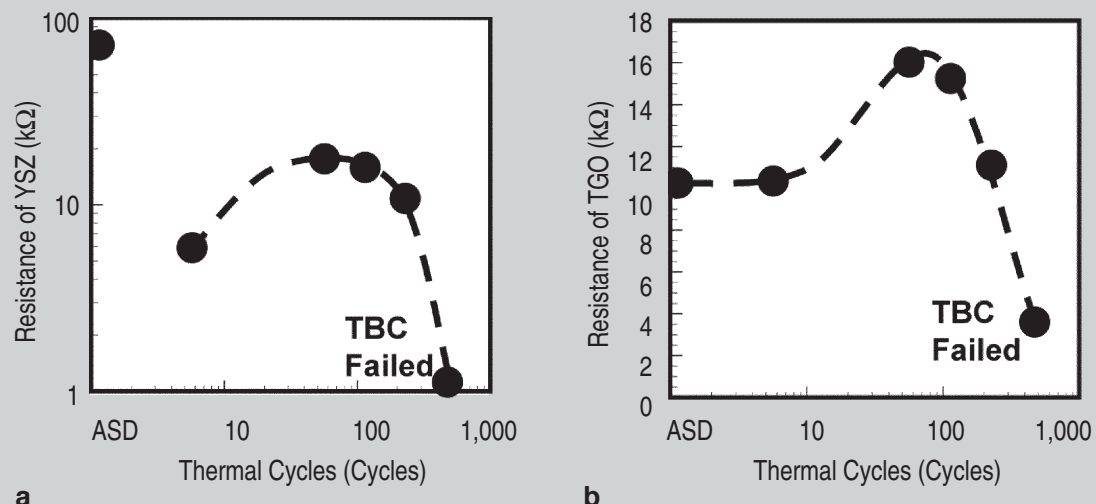

b
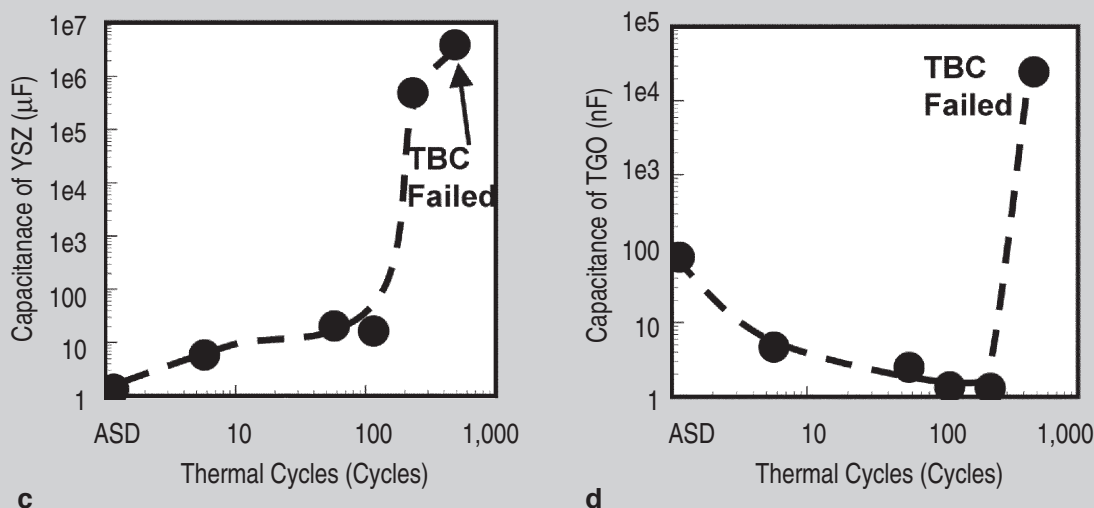

d

Figure 3. The typical variation in the resistance and capacitance of the YSZ and TGO as a function of 1 -hour thermal cycling in air at $1,121^{\circ} \mathrm{C}$ for EB-PVD TBCs.

of photoluminescence spectra as a function of $1 \mathrm{~h}$ thermal cycling at $1,121^{\circ} \mathrm{C}$ (10 min. heat-up, $40 \mathrm{~min}$. dwell, and $10 \mathrm{~min}$. forced-air-quench) for an EB-PVD TBC with (Ni,Pt)Al bond coat and CMSX-4 superalloy substrate. While the failure of the TBC specimen occurred after 420 cycles, a detectable increase in luminescence associated with the stress relief of the TGO scale emerged starting at 350 cycles $^{27}$ underneath the YSZ topcoat. After 400 cycles, more than half of 20 randomly selected non-destructive measurements detected the localized stress relief associated with sub-critical damage in the TGO scale. ${ }^{27} \mathrm{~A}$ corresponding microstructural analysis reveals that there is significant damage in the TGO scales prior to the final failure. The damage modes observed included ratcheting and/or cracking from out-of-plane tensile stress in the vicinity of asperities in $(\mathrm{Ni}, \mathrm{Pt}) \mathrm{Al}$ grain boundary ridges. ${ }^{2,3,28}$

Electrochemical impedance spectroscopy is an NDE technique that measures electrochemical impedance of materials with an applied voltage with varying frequency. The electrochemical impedance characteristics of TBCs may depend on the thickness and microstructure of the YSZ coating, the thickness and microstructure of the TGO, and potentially, the damage at critical interfaces in the vicinity of the TGO. ${ }^{29-31}$ Figure 3 represents a typical evolution in the electrochemical resistance $(\mathrm{R})$ and capacitance $(\mathrm{C})$ of the YSZ topcoat and the TGO scale. In this study, EB-PVD TBCs with NiCoCrAlY bond coats and IN738 superalloy substrates were tested using the $1 \mathrm{~h}$ thermal cycle at $1,121^{\circ} \mathrm{C}$. The failure of the TBC specimen occurred after 419 cycles. ${ }^{29}$ There was an initial increase in the $R_{Y S Z}$ and an initial decrease in the $\mathrm{C}_{\mathrm{YSZ}}$ with thermal cycling. The $\mathrm{R}_{\mathrm{TGO}}$ and $\mathrm{C}_{\mathrm{TGO}}$ also exhibited an initial increase and decrease, respectively. Experimental results based on a sintering study of monolithic YSZ with open pores and isothermal/cyclic oxidation study of $\mathrm{Al}_{2} \mathrm{O}_{3}$-forming alloys have demonstrated that the initial variation in the $\mathrm{R}_{\mathrm{YSZ}}, \mathrm{C}_{\mathrm{YSZ}}, \mathrm{R}_{\mathrm{TGO}}$, and $\mathrm{C}_{\mathrm{TGO}}$ with high-temperature exposure 
can be attributed to the sintering of the YSZ and the growth of the TGO scale. ${ }^{31,32}$ In fact, the thickness of the TGO scale and the $\mathrm{C}_{\mathrm{TGO}}$ were inversely related, as the theory predicts. With further thermal cycling, gradual decreases in $\mathrm{R}_{\mathrm{YSZ}}$ and $\mathrm{R}_{\mathrm{TGO}}$ were observed as well as abrupt increases in the $\mathrm{C}_{\mathrm{YSZ}}$ and $\mathrm{C}_{\mathrm{TGO}}$. These changes correlated to the damage within the TBC, through which the conductive electrolyte can penetrate and shortcircuit with a conductive metallic substrate. This correlation between damage and electrochemical impedance was also demonstrated using a sinterand-quench study of monolithic YSZ with open pores, and isothermal/cyclic oxidation study of $\mathrm{Al}_{2} \mathrm{O}_{3}$-forming alloys. $^{31,32}$ In addition, EIS has demonstrated its potential to examine the processing-dependent changes in the microstructure of TBCs, including thickness, chemistry, and porosity. ${ }^{30}$

\section{NANO-MICROSCALE CHARACTERIZATION BY TEM/STEM VIA FIB-INLO}

Most microstructural analysis of TBCs has relied on qualitative correlation based on resolution-limited x-ray diffraction, and SEM with EDS. However, recent developments in nano- and microstructural evaluation techniques have opened up new ventures. For example, a TEM/STEM analysis carried out using focused ion beam-in-situ lift-out (FIB-INLO) for the specimen preparation is particularly useful for fragile specimens such as TBCs. ${ }^{33-35}$

In preparing the site-specific TEM specimen of TBCs using FIB-INLO, the cross-sectional samples are embedded in transparent cold-setting epoxy, and ground using 600-grit $\mathrm{SiC}$ paper, followed by polishing with diamond paste down to $1 / 4 \mu \mathrm{m}$. The polished surface of the specimens is then sputter coated with Au-Pd to create adequate conduction during FIB imaging and milling operations. First, a wedgeshaped, site-specific specimen is cut free from the bulk material by means of FIB milling. The sample is then attached to the in-situ tungsten probe using ion-beam assisted platinum chemical vapor deposition (CVD). Next, the ion-beam assisted platinum CVD is used to attach the sample to a $2 \mathrm{~mm} \times 1 \mathrm{~mm}$ copper TEM grid that had been previously cut to accommodate access to the grid with the in-situ tungsten probe. Once it is secured to the TEM grid, the sample is milled free from the in-situ tungsten probe and then milled to electron transparency. The sequential images of the specimen preparation via FIB-INLO are presented in Figure 4.

Once the TEM specimen is prepared using FIB-INLO, the nanostructure and microstructure of the TBCs can be analyzed using TEM and STEM techniques. In this study, a Philips/FEI Tecnai F30 300KeV TEM, equipped with high-angle annular dark-field (HAADF) and $\mathrm{X}$-ray energy-dispersive spectroscopy (XEDS) was employed to examine the microstructure of the as-coated and thermally cycled TBCs. ${ }^{33-35}$ In these studies, HAADF (i.e., analogous to backscatter-electron imaging), electron diffraction, and fast-Fourier transformed (FFT) diffractograms were employed to identify phase constituents, particularly the polymorphic make-up of the $\mathrm{Al}_{2} \mathrm{O}_{3}$ in the TGO scale, and were correlated to the non-destructive phase identification via PSLS. ${ }^{33}$

Figure 5 shows the bright-field image of thermally cycled EB-PVD TBC with grit-blasted $(\mathrm{Ni}, \mathrm{Pt}) \mathrm{Al}$ bond coat, a thick TGO (nearly $8 \mu \mathrm{m}$ ) scale, and the development of extensive decohesion at the YSZ/TGO interface after 645 10-h thermal cycles at $1,038^{\circ} \mathrm{C} \cdot{ }^{27}$ No apparent
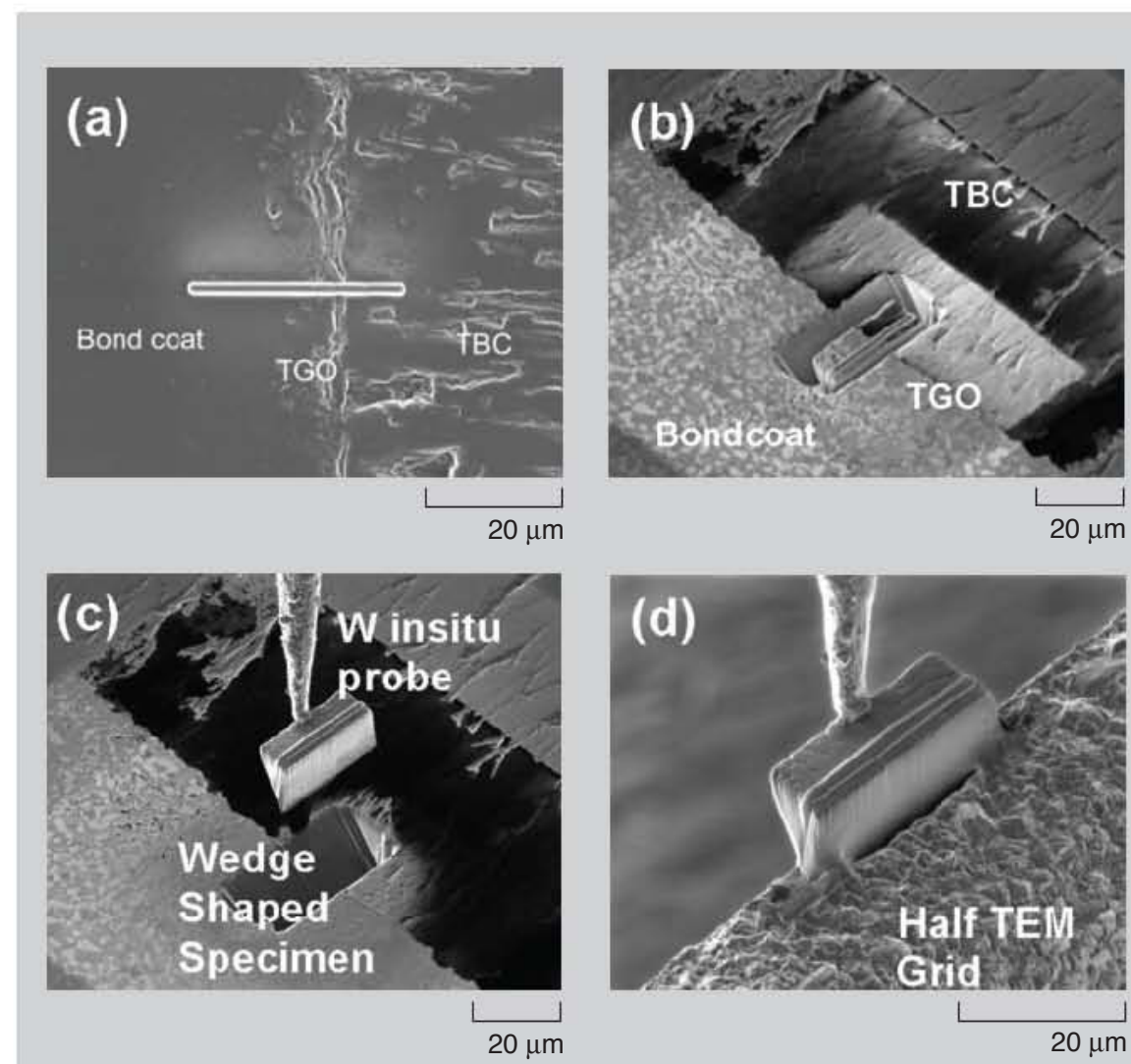

Figure 4. Secondary electron FIB images showing the sequence of the FIB INLO TEM specimen preparation process for a representative TBC specimen. ${ }^{33}$

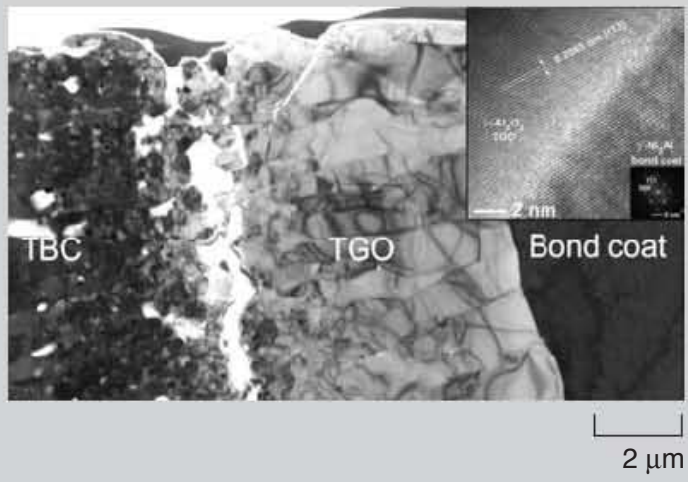

Figure 5. A bright-field TEM micrograph of an intact EB-PVD TBC specimen after 645 10-h thermal cycles at $1,038^{\circ} \mathrm{C}$. Extensive decohesion at or near the YSZ/TGO $\left(\alpha-\mathrm{Al}_{2} \mathrm{O}_{3}\right)$ interface was observed. The FFT diffractogram (inset) from the bond coat corresponds to that of $\gamma^{\prime}-\mathrm{Ni}_{3} \mathrm{Al}$ solid-solution phase. ${ }^{34}$ 


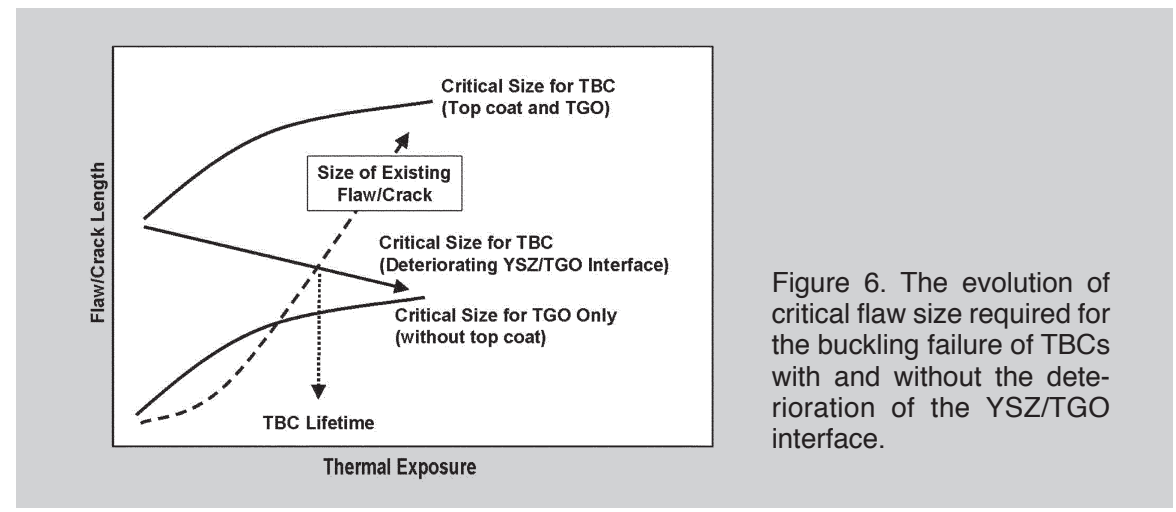

damage was observed at the TGO-tobond-coat interface as illustrated by the high-resolution image presented in the inset of Figure 5. The formation of voids/decohesion at the YSZ/TGO interface has been observed frequently via TEM/STEM examination as a function of thermal exposure. ${ }^{33}$ For the material system under consideration, the constrained volumetric changes associated with the polymorphic transformation of $\mathrm{Al}_{2} \mathrm{O}_{3}$ and morphological change of TGO scale (i.e., rumpling and/or ratcheting) may cause this damage at the YSZ/TGO interface.

Observation of decohesion at the YSZ/TGO interface in Figure 5 warrants a further discussion since this set of samples displayed an interesting failure evolution not documented previously. Delamination buckling is a fairly complex failure mechanism, where a crack reaching a critical size allows the coating to release its strain energy by buckling. Once the coating has buckled, the configuration becomes unstable, resulting in continued crack and buckle propagation, ${ }^{36,37}$ often leading to spallation. A thicker coating is more resistant to buckling, but it can store more energy for potentially driving a crack once the instability is reached.

The presence of a YSZ topcoat suppresses the buckling of the TGO scale, provided that the YSZ/TGO interface remains adhered, as illustrated in Figure 6. In other words, the critical flaw size required for TBC (YSZ+TGO) is larger than that for TGO only. With deterioration of the YSZ/TGO interface, as observed by TEM/STEM, the buckling failure of $\mathrm{TBC}$ requires a smaller flaw (or a crack) size (e.g., critical enough just for the TGO) with the addition of more thermal cycling (i.e., increasing strain energy release rate) as illustrated in Figure 6. Thus, if the amount of voids increases to a critical level, the YSZ is not suppressing the TGO and the TGO is free to buckle. The results can be dramatic large-scale buckling and spallation.

\section{ACKNOWLEDGEMENTS}

Yongho Sohn would like to thank the University Turbine Systems Research (No. 02-01-SR103) of the U.S. Department of Energy(DE-FC26-02NT41431) and the Faculty Early Career Development (CAREER) Program of the National Science Foundation (DMR0238356) for financial support. Anette M. Karlsson would like to thank the Office of Naval Research (N0001404-1-0498) for its financial support via the Young Investigator Award.

\section{References}

1. R.A. Miller, J. Thermal Spray Technol., 6 (1997), p. 35.

2. A.G. Evans etal., Prog. Mater. Sci., 46 (2001), p. 505. 3. N.P. Padture, E.H. Jordan, and M. Gell, Science, 296 (2002), p. 280.

4. P.K. Wright, Current Opinions in Solid State Mater. Sci., 4 (1999), p. 255.

5. V.K. Tolpygo, J.R. Dryden, and D.R. Clarke, Acta Mater., 46 (1998), p. 927.

6. T. Tomimatsu, S. Zhu, and Y. Kagawa, Acta Mater., 51 (2003), p. 2397.

7. J.A. Nuchka et al., Surf. Coat. Technol., 163/164 (2003), p. 87.

8. G.M. Kim et al., Scr. Mater., 46 (2002), p. 489.

9. U. Schulz et al., J. Eng. Gas Turbines Power, 124 (2002), p. 229.

10. O. Unal, T.E. Mitchell, and A.H. Heuer, J. Am. Ceram. Soc., 77 (1994), p. 984.

11. M.R. Brickey and J.L. Lee, Oxi. Met., 54 (2000), p. 237.

12. A.H. Carim et al., Mater. Sci. Eng. A, A334
(2002), p. 65.

13. U. Schulz et al., Surf. Coat. Technol., 146/147 (2001), p. 117

14. K.S. Murphy, K.L. More, and M.J. Lance, Surf. Coat. Technol., 146/147 (2001), p. 152.

15. C. Mennicke, D.R. Mumm, and D.R. Clarke, $Z$. Metallkd., 90 (1999), p. 12.

16. D.R. Mumm et al., Acta Mater., 52 (2004), p. 1123.

17. Q. Ma and D.R. Clarke, J. Am. Ceram. Soc., 76 (1993), p. 1443.

18. R.J. Christensen et al., Appl. Phys. Lett., 69 (1996), p. 3754.

19. D.R. Clarke, J.R. Christensen, and V.K. Tolpygo, Surf. Coat. Technol., 94/95 (1997), p. 89.

20. Y.H. Sohn et al., Surf. Coat. Technol., 146/147 (2001), p. 102.

21. Y.H. Sohn et al., Metall. Mater. Trans. A, 31A (2000), p. 2388.

22. K.W. Schlichting et al., Mater. Sci. Eng. A, A291 (2000), p. 68.

23. A. Atkinson, A. Selcuk, and S.J. Webb, Oxi. Met., 54 (2000), p. 371.

24. A. Selcuk and Atkinson, Mater. Sci. Eng. A, A335 (2002), p. 147.

25. A. Selcuk and A. Atkinson, Acta Mater., 51 (2003), p. 535.

26. V.K. Tolpygo and D.R. Clarke, Mater. High Temp., 17 (2000), p. 59.

27. B. Franke et al., unpublished research (2004).

28. A.M. Karlssen, J.W. Hutchinson, and A.G. Evans, Mater. Sci. Eng. A, A351 (2003), p. 244.

29. B. Jayaraj et al., Surf. Coat. Technol., 177/178 (2004), p. 140

30. S. Vishweswaraiah et al., Thermal Spray 2003: Advancing the Science and Applying the Technology, ed. B.R. Marple and C. Moreau (Materials Park, $\mathrm{OH}$ : ASM International, 2003), pp. 1487.

31. B. Jayaraj et al., Mater. Sci. Eng. A, A372 (2004), p. 278.

32. S. Vishweswaraiah et al., unpublished research (2004).

33. S. Laxman et al., Surf. Coat. Technol., 177/178 (2004), p. 121

34. B. Kempshall et al., Thin Solid Films, (2004) in press.

35. A.J. Burns et al., Surf. Coat. Technol., 177/178 (2004), p. 89.

36. A.G. Evan, J.W. Hutchinson, and M.Y. He, Acta Mater., 47 (1999), p. 1413.

37. S.R. Choi, J.W. Hutchinson, and A.G. Evans, Mech. Mater., 31 (1999), p. 431. 